\title{
Light and Shadow—Postgender Intersubjectivity in The Left Hand of Darkness
}

\author{
ZHANG Na \\ Guangdong University of Foreign Studies, Guangzhou, China \\ Guangdong Science Center, Guangzhou, China
}

\begin{abstract}
The Left Hand of Darkness (abbr. LHD) is composed by Ursula Le Guin as a "thought experiment" to explore the postgender world on the planet of Gethen. By eradication of sexual difference and embracing the biological fluidity and psychological androgeny, dualism is deconstructed, and a postgender intersubjective space is reconstructed between Genly Ai and Estraven, interluded by cyborg myth and postgenderism culture narratives. Moreover, Le Guin suggests a possible transformation mode of yin-yang cycle from psychoanalytic light and shadow.
\end{abstract}

Keywords: postgenderism, intersubjectivity, cyborg, science fiction, narratology

\section{Introduction}

On the issue of gender, Ursula Le Guin performs the "thought experiment" of postgender narrative in her science fiction LHD (1969) to go beyond the binary thinking of gender. In Le Guin's nonfiction The Language of the Night-Essays on Fantasy and Science Fiction (1979), influenced by the psychoanalytic theories of C. G Jung and Jacques Lacan, she explains the damaging effect of projection from subject to the other as to objectify the other, ensued by the establishment of power relationship, which further impoverish one's own reality and alienated oneself. In Le Guin's words, “our curse is alienation, the separation of yang from yin”. (Le Guin, 1992, p. 12) Space voyage is the process of going into the other's psychic abysses, also for the purpose of gaining understanding of the subject himself. To reach the other, the subject goes into himself. Le Guin's tentative methodology to gender problem is to turn the other gender into another subject, a bypass of recognition and identification through the other's self, to make the whole process an Yin and Yang circle, thereby changing dualism into integration and integrity. Types of gender are not subject and others, but interact intersubjectively, like Yin and Yang, light and shadow, as an undivided cycle of postgender, sexless intersubjective humanity.

The concept of intersubjectivity, which has been brought into psychoanalysis from philosophy, refers to a field of intersection between two subjectivities, the interplay between two different subjective worlds to define the analytic situation. Intersubjective theory, according to the contemporary feminist intersubjectivity theorist Jessica Benjamin, postulates that the other must be recognized as another subject in order for the self to fully experience his or her subjectivity in the other's presence (1995). The inherent sexual difference of bigenderism

ZHANG Na, Ph.D. Candidate in 20th Century American Literature, Guangdong University of Foreign Studies; Guangdong Science Center. 
perpetually returns to dualism, serving as a "symbolic violence” (Butler, 1990, p. 194) for all who are shaped by it. Nonetheless, gender theorists' vocabulary shifts from "doing gender" to "doing difference” (West \& Zimmerman, 1987; Fenstermaker, West, \& Smith, 2002).

In order to thoroughly deconstruct binary thinking, a radical alternative in line with queer theories' original deconstructive impulses is offered by postgenderism to eradicate difference through means of neurotechnology, biotechnology and reproduction technologies to go beyond the gendered bodies, "the hierarchical dualisms ordering discourse in 'the West' since Aristotle ... have been cannibalized ... they have been 'techno-digested'” (Haraway, 2000, p. 302), as "to transgress dualist philosophy ... feminist analysis of subjectivity and identity should take corporeality ... as its point of departure” (Nicholas, 2014, p. 9). Postgenderism is a radical interpretation of the feminist critique of patriarchy and gender, and the genderqueer critique of the way that binary gender constrains individual potential and our capacity to communicate with and understand other people (Dvorsky \& Hughes, 2008), thus functions to achieve intersubjectivity on the dimension of gender, which through eradication or rejection of sexual difference, reconstructing an alternative bypass, intersubjectivity can be understood with an androgynous relational existence therein.

LHD is mainly narrated by the male envoy from the Ekumen of Known Worlds Genly Ai with the mission to enlist two hostile countries of the planet Gethen, Karhide and Orgoreyn, to join the Ekumen. Ai is bewildered by the internal political states and sexual ambiguity of the people on Gethen. The whole narrative intertwines with the development of the relations between Genly Ai and Estraven from Karhide. Estraven is an enigma to Ai at the beginning, as the plot develops, several myths and legends penetrate into the narration, foreshadowing their relations more than once. After Estraven's rescue of Ai from the Pulefen Farm in Orgoretn, the narration is conveyed through dual perspectives of Ai and Estraven in sequence. Their harsh escape to the ice bonds them as one. Estraven dreams a dream about his died elder brother talking to him, later in Ai's narration, proving to be Ai's mindspeech to Estraven. Ai and Estraven, as genderly alien to each other, over time, goes beyond the sexual shell, the inner, sexless personality emerges. Estraven's last word upon death calls his brother's name "Arek" to Ai, suggesting an elusive fraternal kinship with Ai.

\section{The Arbitrariness of Gender}

The gender issue of LHD is targeted intensively in "Chapter 7. The Question of Sex", a social observation made by a female investigator of the first Ekumenical landing party on Gethen/Winter. The female investigator regards her one of the "Colonizers" from the Hainish "Normal” group to make an experiment on the alien planet of Gethen, and "theorizes” about Gethenian sexual physiology. Compared with Genly Ai, this female scientist seems much less connected to Gethenian people, remaining as an isolated self gazing on an impenetrable periphery position about the hypothetical experiment objects' somer-kemmer (latent-estrus) cycle as well as how the whole Gethenian social structure is shaped by it.

The somer period lasts for $4 / 5$ of the cycle, during which Gethenian are not sexually motivated at all, in a sexless state. In the first phrase of kemmer (secher), Gethenian remains completely androgynous until the individual finds a partner in kemmer, and one partner either a male or female hormonal dominance is established, while the partner, triggered by the change, takes on the other sexual role, and entering the second phase of kemmer (thorharmen) in a mutual process of establishing sexuality and potency. Gender is taken arbitrarily, 
sensitive to and even decided to the context, as observed, "the dominant factor in Gethenian life is not sex or any other human thing: it is their environment, their cold world” (Le Guin, 1969, p. 50). To fight against the relentlessly cold weather in Gethen, ambisexuality is adaptive to conserve energy, resulting in a blurred boundary between human and mammals, as both taking an estrous cycle. Such a similarity of sexual mode between human and animal can be explained by Donna Haraway’s “A Cyborg Manifesto”, in which she signals three boundary breakdowns, the first one being the the transgressed boundary between human and animal, celebrating the new status of cyborg's bestiality as traces of nature and culture's connection (2000, p. 293).

As an effect, the Gethenian society has taken multifaceted configuration of a Utopian postgenderism intersubjective vision. There is no myth of Oedipus on Winter, since a child has no psycho-sexual relationships to his mother or father. Burden and privilege are shared out equally; everybody has the same risk to run or choice to make. Gender essentialism and the whole tendency to dualism is lessened or changed. In this way, Gethenian are cyborgs, creatures in a post-gender world, having no truck with bisexuality, pre-oedipal symbosis or unalienated labour (Haraway, 2000, p. 293).

Greater biological fluidity and psychological androgyny allow the Gethenian to explore both masculine and feminine aspects of personality. The dynamic balance is achieved and radically gendered behaviors such as female depression and male aggression could be avoided, as that Gethenians seem not to be very aggressive and never have a war. The androgynous ethics embraces moderation by avoiding extremes. Not restricted to the aspect of sex/gender, the androgynous thinking, like binary thinking on the earth, is so pervasive, such as Gethenian's view on time manifested by the discipline of the eternal presence and attitude against progress.

\section{Cyborg Countermyth Making}

Parallel to Genly Ai's exploitative adventure on Gethen, there exists another line of narration, anchronous and mythical, stretching back to the remote past of Gethen. Except chapter 7, there are 5 chapters of them, chapter 2, 4, 9, 12, 17, different from Genly Ai and Estraven's real adventure, these 5 chapters are narrated with high density and metaphysically, which can be understood as Le Guin's effort in constructing a reliable Gethenian culture, a cyborg myth system, one brick over another, until the last brick of creation in the depth. In this way, the boundary is permeable between tool (stories) and myth. Indeed, myth and tool (stories) mutually constitute each other (Haraway, 2000, p. 302).

In "Chapter 17. An Orgota Creation Myth”, the apparent subversion of central myths of Western culture origin is the absence of God. In this creation myth, at the beginning, there is the sun and the ice, no God, only nature. The fathers, after all, are inessential (Haraway, 2000, p. 293). Human come from nature, commits fratricidal and incest, their offsprings come from the house of flesh/corpse and are doomed to be followed by shadow/death. Life comes from death, thus death/inanimate is the mother, as Haraway suggests, "Machine was mother here, not Eve before eating the forbidden fruit” (2000, p. 312). Cyborgs' possibility to survive not because of the innocence, but because the ability to live on the boundaries to write without the founding myth of original wholeness. The cyborg body is not innocent, born not in the garden but in the graveyard, the house of dead bodies.

In "Chapter 12. On Time and Darkness", Gethenian view on time is explained, "there is neither source nor end, for all things are in the Center of Time”, referring to the Gethenian Calender with the basic year as the 
current year, the Year One, as well as in its creation myth, "they are in the middle of time” (Le Guin, 1969, p. 117), plus the religious Handdara disciplines of Presence, it can be drawn that from the their beginning of existence, Gethenian life focuses on the present, rather than the future or the past. Their existence lies in the presence, in line with Haraway's postgender cyborg world, "which is perhaps a world without genesis, but maybe also a world without end” (2000, p. 292). In Gethenian myth, in the beginning, there was the sun and the ice, and there was no shadow. In the end, the sun will devour itself and shadow will eat light, and there will be nothing left but the ice and the darkness. Humans are in the middle of time, a piece of darkness follows him about wherever he goes by daylight.

Moreover, Incest and fratricide appear more than once in Gethenian myths and legends with multiple configurations. Copulating with sibling is the source of procreation in the creation myth, while brothers incest and vowing kemmer (getting marriage) is the taboo leads to more deteriorated suicide and self-exile in the legend in "Chapter 2. The Place Inside the Blizzard". Brothers Killing is driven by a sort of "homophobia” or fear of the others, while murder of hearth-brothers is for self-defending and leads to the integration (boundary elimination) between the Domain of Stok and the Domain of Estre, but the murderer, Estraven is cursed by the name "Estraven the Traitor" thereafter. Incest and fratricide are two opposite polarized behaviors in kinship relations, and often appear in the same narrative to constitute a pair of opposite relations as overrating of kinship (incest): underrating of kinship (fratricide) (Strauss, 1955). However, in "Chapter 2. The Place Inside the Blizzard” and "Chapter 9. Estraven the Traitor”, Le Guin's mode of mythical telling composed by incest plus fratricide is divided to incest in the former (patricide is degenerated to suicide) and patricide in the latter (incest is alleviated by interracial kemmer). Actually these two chapters should be viewed as a bundle, functioning together to foreshadow the developing story at present, indicating the intimate relations between Genly Ai and Estraven.

\section{“Gendered” Pronoun and Sequential Narration}

Curiously enough, in the postgender narrative of LHD, all the pronoun referring to Gethenian, either Estraven, Karhide King Argaven XV, Faxe the foreteller, Meshe is "he”. This is a tradition cultivated by the first investigator group from Ekumen. They choose to use "he" instead of "it", for that Gethenian are not neuters, they are potentials or integrals (Le Guin, 1969, p. 49). They use "he” for Gethenians in somer for the same reason as the masculine pronoun is used in referring to a transcendent god, "it is less defined, less specific,than the neuter or the feminine” (Le Guin, 1969, p. 49). In this way, one is respected and judged beyond gender, only as a human being.

Nearly twenty years after LHD’s first publication in 1969, Le Guin writes an afterword particularly addressing the haunting and bedeviling gender of LHD's pronouns, recollecting her thought when writing LHD in 1967, "I called them all 'he'. I believed then that the masculine pronoun in English was genuinely generic, including both male and female referents. This is a pleasant and convenient belief” (Le Guin, 1994), in line with the female investigator in the first Ekumenical landing party on Gethen. In this way, the female investigator functions as the implied author representing Le Guin's voice. The implied author only appears in chapter 7 expressing the author's thinking on the postgender reference of "he" instead of gendered one used in our mundane world, whereas the pronoun "he" is widely applied among the text, her voice seems to be overwhelmed and ignored. In the afterwords, Le Guin argues that even s/he, the best of the lot, is bisexual rather than genderless, 
in capable of depicting the postgender beings on Gethen. Besides, considering Freud's use of pronoun, when the patient is active, Freud uses the male pronoun; when simply ill, he uses the feminine pronoun (Benjamin, 1998, p. 11), thus using the male pronoun can serve as a means to endow the person in reference with an active subjective status, no matter what gender the person in reference is.

Another textual feature of postgenderism intersubjectivity lies in the sequential narration in chapter 10 and 11, chapter 13 and 14, as well as in chapter 14 and 15 narrated by Genly Ai and Estraven in sequence, embedded in chapter 1, 3, 5 and chapter 6, 8, as well as chapter 18, 19, 20 narrated by Gengly Ai alone. In the initial chapters, articulation is merely made from Genly Ai, situating Estraven as the alien other. Genly Ai centers on the experience of his self, feeling "cold, unconfident, obsessed by perfidy, and solitude, and fear” (Le Guin, 1969, p. 15). Estraven is portrayed by Genly Ai as the darkest, with no loyalties and untrustworthy. As the other, Estraven remains speechless and silent, until the sequential narration from chapter 10. Their movement paths begin to converge and together encounter the same bewilder surroundings. Dual-voices are established to narrate the sharing temporal and spatial experience from Genly Ai and Estraven's point of view respectively. Estraven achieves the "primal leap" from body to speech,as the inarticulate other, he begins to articulate in real sense as the narrator in chapter 11, 14, 16 and is enfranchised thereby.

\section{Mutual Recognition and Intersubjective Space}

As mentioned in the last section, sequential interaction between Genly Ai and Estraven is performed as represented in alternating narrators. As this mode evolves, misunderstanding is gradually melted away, as if their gendered shell falls down, the inner self of humanity begins to emerge, then comes the climax of Genly Ai and Estraven's mutual recognition. The exchange of foretelling of Gethen and mindspeech of Ekumen is fully achieved by mutual learning. Different from Karhide King Argaven XV's fear of the other and Faxe the teller's preference to unlearning than leaning to change the world, Estraven is eager to learn Genly Ai's mindspeech, in the same way as Genly Ai's willingness to learn the Karhide foretelling, as narrated by Genly Ai, "mindspeech was the only thing I had to give Estraven, out of all my civilization, my alien reality in which he was so profoundly interested” (Le Guin, 1969, p. 120). Genly Ai’s attitude towards Estraven shifts from misogyny/homophobia to acceptance,

(Estraven) was the only one who had entirely accepted me as a human being: who had liked me personally and given me entire personal loyalty: and who therefore had demanded of me an equal degree of recognition, of acceptance...I had not wanted to give my trust, my friendship to a man who was a woman, a woman who was a man. (Le Guin, 1969, p. 121)

Genly Ai uses mindspeech to call Estraven’s name “Therem!” during the latter’s sleep, what Estraven heard is his lost bother Arek's calling him in the dream. After awakening, Estraven reveals that Arek was his full brother who would have been Lord of Estre, but died 14 years ago and there is something happened between this pair of siblings, which results in Estraven's self-exile from home. Until now, the present is precisely connected to the past legend of "Chapter 9. Estraven the Traitor". But there remains residues of ambiguities concealed in darkness that resists further disclosure, "intimacy of mind established between us was a bond, indeed, but an obscure and austere one, not so much admitting further light as showing the extent of the darkness" (Le Guin, 1969, p. 134). 
The communicative speech is established not until the moment of Genly Ai and Estraven's mutual recognition by the means of mindspeech. The communicative speech establishes a space of dialogue potentially outside the mental control of either or both participants, it is a site of mediation, the Lacan's "third term", or Benjamin's “intersubjective space" (1988), or Ogden's "analytic third” as the idea of a co-created yet independent relationship of two subjectivities. Upon Estraven's doomed death (probably suicide) as a self-punishment of incest and vowing kemmer with his brother, his last word is calling back Genly Ai by his brother's name "Areck!” Articulating the name functions crucially in LHD culture narrative, as illustrated in the tale of "Chapter 2. The Place Inside the Blizzard”, denial one's name can make the earth being blighted with illness, whereas recognition of one's name can resume the land to prosperous again. Genly Ai and Estraven's calling each other's name suggests the fulfillment of their intersubjective mutual recognition and the establishment of the intersubjective space.

This postgender intersubjective space is gradually constructed through narration, which encompasses light and darkness, female and male, Genly Ai and Estraven, life and death and so on. The contour is figured out by a Gethenian poem articulated instinctively,

\author{
Light is the left hand of darkness \\ and darkness the right hand of light. \\ Two are one, life and death, lying \\ together like lovers in kemmer, \\ like hands joined together, \\ like the end and the way. (Le Guin, 1969, p. 115)
}

Coincidentally, Genly Ai also describes a symbol, the yin-yang circle found on Earth, that is highly compatible to Estraven's lines above. Ai draws “the double curve within the circle, and blacked the yin half of the symbol... It is yin and yang. Light is the left hand of darkness... Light, dark. Fear, courage. Cold, warmth. Female, male... Both and one. A shadow on snow" (Le Guin, 1969, p. 130). Thus the constructed postgender intersubjective space takes the very shape of Oriental Taoism yin-yang diagram. Different from the integration of genders in dualist world, where it is mostly achieved by bodily intercourse, truly integration in LHD goes between Genly Ai and Estraven trough the means of mutual recognition. Both Ai and Estraven embark on discursive journey going from the self's conscious light to the other's unconscious darkness, and return to his own self to achieve a further identification. After mutual recognition, the two subjects of Ai and Estraven once more perpetually separated by the boundary of life and death, but as indicated by the poem or by the yin-yang cicle, "two are one, life and death, lying together like lovers in kemmer,like hands joined together, like the end and the way".

\title{
Conclusion
}

After LED, in her nonfiction Dancing at the Edge of the World (1990), Le Guin puts forward the carrier bag theory of fiction. Differing with the arrow/spear "proper shape of narrative", she argues that the fitting shape of the novel might be a sack/bag, since that "a book holds words. Words hold things. They bear meanings" (1990, p. 169). Technology and science are redefined as primarily cultural carrier bag, rather than weapon of domination like linear, progressive, time’s arrow mode. As a pleasant effect, "science fiction can be seen as a far less rigid, 
narrow field, not necessarily Promethean or apocalyptic at all, and in fact less a mythology genre than a realist one” (1990, p. 170). The established postgender intersubjective space is like such a carrier bag, a container, inside which each element is transformed from one polar to its opposite, generating a state of fluidity between conventional binary oppositions like male and female, subject and object. Moreover, the overall shape of this postgender intersubjective space as a yin-yang circle subverts the traditional linear narrative of science fiction, expanding the genre of science fiction to contain both elements of mythology and reality, which is also Le Guin's contribution to the narrative of science fiction.

\section{References}

Benjamin, J. (1988). The bonds of love: Psychoanalysis, feminism and the problem of domination. New York: Pantheon.

Benjamin, J. (1995). Recognition and destruction: An outline of intersubjectivity. In Like subjects, love objects: Essays on recognition and sexual difference (pp. 1-10). New Haven: Yale University Press.

Benjamin, J. (1998). The primal leap of psychoanalysis from body to speech: Freud, feminism and the vicissitudes of the transference. In Shadow of the other: Intersubjectivity and gender in psychoanalysis (pp. 1-34). New York \& London: Routledge.

Butler, J. (1990). Gender trouble: Feminism and the subversion of identity. New York \& London: Routledge.

Dvorsky, G., \& Hughes, J. (2008). Postgenderism: Beyond the gender binary. Postgender. IEET Monograph Series, 1-18.

Fenstermaker, S., West, C., \& Smith, E. D. (2002). Doing gender, doing difference: Inequality, power and institutional change. New York \& London: Routledge.

Haraway, D. (2000). A cyborg manifesto: Science, technology and socialist-feminism in the late twentieth century. In D. Bell and B. Kennedy (Eds.), The cybercultures reader (pp. 291-324). London \& New York: Routledge.

Le Guin, K. U. (1969). The left hand of darkness. New York: Ace Books.

Le Guin, K. U. (1990). Dancing at the edge of the world: Thoughts on words, women, places. New York: Harper \& Row Publishers Inc.

Le Guin, K. U. (1992). The language of the night: Essays on fantasy and science fiction. New York: Harper Collins Publishers.

Le Guin, K. U. (1994). Afterword to The Left Hand of Darkness-The gender of pronouns. Retrieved from http://theliterarylink.com/afterword.html

Nicholas, L. (2014). Philosophical arguments for post-gender ontological ethics. UK: Palgrave Macmillan.

Strauss, L. C. (1955). The structural study of myth. Myth: A symposium. The Journal of American Folklore, 68(270), 428-444.

West, C., \& Zimmerman, D. (1987). Doing gender. Gender and Society, 1(2), 125-151. 